\title{
In vivo and in vitro inhibition of human liver cancer progress by downregulation of the $\mu$-opioid receptor and relevant mechanisms
}

\author{
JIN LU ${ }^{1}$, ZEFENG LIU ${ }^{2}$, LINGLING ZHAO ${ }^{1}$, HUIMIN TIAN ${ }^{1}$, XIUHUA LIU ${ }^{1}$ and CHANGJI YUAN ${ }^{1}$ \\ Departments of ${ }^{1}$ Hematology and Oncology, ${ }^{2}$ General Surgery, First Hospital, \\ Jilin University, Changchun 130021, P.R. China
}

Received May 28, 2013; Accepted July 12, 2013

DOI: $10.3892 / o r .2013 .2640$

\begin{abstract}
Opiates have long been used as analgesics to relieve pain associated with various medical conditions. $\mu$-opioid receptor (MOR) is the main member of the opioid receptor super-family and the excitation or overexpression of MOR promotes the proliferation of many kinds of tumor cells. It was found in our previous studies that MOR was highly expressed in the tissue and cells of human liver cancer. However, the impact of MOR on the progress of human liver cancer remains unknown. The purpose of this study is to investigate the impact of MOR downregulation on the progress of human liver cancer and the mechanisms involved. RNA interfering or specific inhibitor was administered to downregulate the MOR in human hepatocellular carcinoma cells and it was found that the proliferation of hepatocellular carcinoma cells was significantly inhibited with the increase of the apoptotic rate, while the cell cycle was blocked in G0/G1 phase and the tumor growth in the mice was retarded. In addition, downregulation of MOR resulted in the increase of phosphorylation of the MKK7 expression and JNK activation. On the contrary, blockade of MKK7 pathway can reverse the antitumor role of MOR. In summary, downregulation of MOR is able to inhibit both in vivo and in vitro human liver cancer progress and it shows potential to be used in cancer therapy.
\end{abstract}

\section{Introduction}

Hepatocellular carcinoma (HCC) accounts for $~ 95 \%$ of the primary liver cancer and is one of the malignant tumors of high malignancy and poor prognosis. As shown in the

Correspondence to: Professor Changji Yuan, Department of Hematology and Oncology, First Hospital, Jilin University, 71 Xinmin Street, Changchun 130021, P.R. China

E-mail: jdyuanchangji@163.com

Key words: $\mu$-opioid receptor, liver cancer, progress, MKK7, JNK signaling pathways epidemic disease statistics, the incidence rate of liver cancer in the world ranks no. 8 among all kinds of cancers, and its mortality ranks no. 4 with $\sim 0.5-1$ million deaths each year. Resection is universally recognized as the best approach to cure liver cancer, but the total 5-year survival rate after the surgery is low with only $34.6 \%$ in terms of large hepatocellular carcinoma and $62.9 \%$ in terms of small hepatocellular carcinoma (1-4).

$\mu$-opioid receptor (MOR) is the main member of the opioid receptor super-family that is extensively distributed in the body. It is found in studies that MOR activation promotes the proliferation of many kinds of cells (5-8) and facilitates the growth of some malignant tumors (9-12) such as lung cancer, breast cancer, neuroblastoma and colon cancer. This means MOR plays an important role in the proliferation and differentiation of various kinds of cells. MOR is found to have apparently higher expression in HCC cells than in the normal liver cells. However, the role that MOR plays in HCC progress has not been reported. In addition, little is known about the mechanism by which MOR promotes tumor growth.

C-jun N-Terminal Kinase (JNK) signal pathway is one of three parallel pathways in the center of the pathway of mitogenactivated protein kinase (MAPK) that plays an important role in regulating the tissue cell reaction, such as cell proliferation and differentiation (13-15). It has been demonstrated by previous studies that MKK7 and MKK4 are two kinases at the upstream of JNK pathway which can activate the JNK signal pathway via the phosphorylation of Tyr and Thr residue (16). However, different from the subtypes of other MAPK, MKK7 on the Thr residue is sufficient and specific to activate JNK pathway which, in turn, activates substrates such as transcription factors or pro-apoptotic proteins (17). Moreover, various studies have demonstrated that MKK7 is indispensable for JNK activation (18). Because of the important role MKK7 plays in JNK pathway activation, it is necessary to explain its role in MOR against HCC.

The purpose of this study was to investigate the impact of downregulating MOR on in vivo and in vitro human liver cancer progress and to explore its possible molecular mechanism. We found the downregulation of MOR was able to inhibit the proliferation of hepatoma cells and significantly retarded the tumor growth. Moreover, it was found that MKK7 
phosphorylation level was increased thus activating JNK. In summary, we have found that downregulation of MOR was able through MKK7-JNK pathway to inhibit the progress of human liver cancer in vivo and in vitro.

\section{Materials and methods}

Experimental specimen. Sixty cases of HCC tissue excised in the surgery of First Hospital of Jilin University from 2009 to 2010 were selected for the experiment which had all been pathologically confirmed to be HCC and the patients had not received any treatment prior to the surgery. At the same time, 20 cases of normal liver tissues from liver trauma and next to the hepatic hemangioma were selected for comparative study. All the specimens have been discussed and approved by the ethics committee of The First Hospital of Jilin University.

Cells, antibodies and reagents. Human liver cancer HepG2 cells and LO2 cells were purchased from ATCC (ATCC, USA), BEL7402 cells were a gift from Laboratory of Molecular Biology of Chinese Academy of Sciences (Shanghai, China). Lipofectamine 2000 was purchased from Invitrogen, USA, siRNA was synthesized by GenePharma (Shanghai, China), and RT-PCR kit [Takara RNA PCR kit (AMV) version 3.0] was purchased from Takara Biotechnology Co., Ltd. (Japan). PI was purchased from Sigma (USA), MOR phosphorylated MKK7, MKK7, phosphorylated JNK and JNK antibody were all purchased from Cell Signaling Technology (USA).

Cell culture. Cells after cell passage was inoculated in the DMEM culture medium (Gibco-BRL, NY, USA) containing $10 \%$ fetal calf serum (Hyclone Laboratories, UT, USA), $100 \mathrm{U} / \mathrm{ml}$ penicillin and $100 \mathrm{U} / \mathrm{ml}$ streptomycin. Then it was cultured in the incubator containing $5 \% \mathrm{CO}_{2}$ and $95 \%$ oxygen at $37^{\circ} \mathrm{C}$.

Cell viability. Cells of various experimental groups in logarithmic growth phase were taken and 6 duplicate wells were set for each group with a negative control group. All the cells were put into $5 \% \mathrm{CO}_{2}$ incubator for further culture prior to color reaction. Each well was added with $20 \mu \mathrm{l}$ of MTT $\left(5 \mathrm{mg} / \mathrm{ml}\right.$ ) and cultured in $\mathrm{CO}_{2}$ incubator for $4 \mathrm{~h}$ before the culture solution was disposed of. DMSO (200 $\mu$ l) was added to each well for room temperature oscillation for $10 \mathrm{~min}$ and the OD values were measured with microplate reader at a wavelength of $490 \mathrm{~nm}$.

Immunohistochemical analysis. Paraffin specimen section was conventionally dewaxed to water and dehydrated with gradient alcohol, for antigen retrieval, incubated for $10 \mathrm{~min}$ in $3 \% \mathrm{H}_{2} \mathrm{O}_{2}$ solution at room temperature. Drowise $5 \mu \mathrm{l}$ of $10 \%$ goat serum was added and then sealed for $10 \mathrm{~min}$ at room temperature. Rabbit anti-human (50 $\mu \mathrm{l})$ MOR monoclonal antibody (1:50) was added and placed at $4^{\circ} \mathrm{C}$ overnight. Biotin labeled goat anti-human antibody (50 $\mu \mathrm{l})$ was added and incubated for $30 \mathrm{~min}$ at room temperature. DAB stain with haematin was applied for 2 min with hydrochloric alcohol differentiation. Dehydration was performed with gradient alcohol. Evaluation was performed by microscopy and images were taken.
siRNA transfection. The cells were inoculated in the 6-well culture plate at the density of $5 \times 10^{5} / \mathrm{ml}$. Cells were cultured in medium free of antibiotics to $>60 \%$ confluence. The culture medium free of serum and antibiotics was replaced. Purified cells were transfected for $24 \mathrm{~h}$ with siRNAs to $\mu$-opioid receptor (MOR siRNAs; Santa Cruz Biotechnology, CA) at a concentration of $20 \mathrm{nM}$. Transfected cells were placed into the $\mathrm{CO}_{2}$ incubator to cultured for $4 \mathrm{~h}$, then the culture medium with serum was used to continue the culture. Non-specific Control siRNA was used as the control group. siRNA interfering efficiency was tested with RT-PCR and western blotting.

$R N A$ extraction and RT-PCR. Instructions of the RNAiso ${ }^{\mathrm{TM}}$ Plus (Takara, Japan) for total RNA extraction were followed, employing the RT-PCR reagent (Takara) for RT-PCR reaction with the steps as shown in the instructions. MOP forward primer: 5'-TCTGGCTCCAAAGAAAAGGA-3', reverse primer: 5'-CAATGCAGAAGTGCCAAGAA-3'. MKK7 forward primer: 5'-GCCAGACTGGGAAGAAATCTG-3', reverse primer: 5'-GGCGGACACACACTCATAAA ACAGA3'. $\beta$-actin forward primer: 5'-CTGGGACGACATGGAGA AAA-3', reverse primer: 5'-AAGGAAGGCTGGAAGAG TGC-3'. PCR reaction system $50 \mu 1$ at the following reaction conditions: $94^{\circ} \mathrm{C} 2 \mathrm{~min}, 94^{\circ} \mathrm{C}$ degeneration $30 \mathrm{sec}, 58^{\circ} \mathrm{C}$ anneal $30 \mathrm{sec}, 72^{\circ} \mathrm{C}$ extension $30 \mathrm{sec}$, total 31 cycles. The PCR product was electrophoresed with $1.0 \%$ agarose gel, then scanned and analyzed with gel imaging system.

Analysis of apoptosis. Trypsin was digested to collect the cells, and the cells were washed twice with pre-cooled PBS, and single cell suspension were prepared. Annexin V and PI staining fluid were added, respectively, in accordance with the steps of the instructions for apoptosis reagent kit (Annexin V-FITC kit, Biosea Biotechnology Co., Beijing, China) for $15 \mathrm{~min}$ at room temperature before the analysis with flow cytometry for apoptosis.

Analysis of cell cycle. Trypsin (0.25\%) was digested to collect the cells and washed with PBS 2 times, then fixed at $4^{\circ} \mathrm{C}$ with $70 \%$ cold ethanol overnight. The ethanol was discarded the following day, and 2 more washes with PBS followed. PI comprehensive dye medium $(1 \mathrm{ml}$ ) (with $10 \mu \mathrm{g}$ of RNase, and $5 \mu \mathrm{l}$ of Triton $\mathrm{X}-100)$ was added, then stored in a dark for $30 \mathrm{~min}$ at $4^{\circ} \mathrm{C}$ before analysis with flow cytometry (BectonDickinson, USA).

Western blot assay. Total protein was separated with SDS-PAGE. Proteins were placed to PVDF membranes, with the semidry method, and seal with $5 \%$ skim milk powder at $4^{\circ} \mathrm{C}$ overnight. The membrane was washed with TBST and the first antibody added at $37^{\circ} \mathrm{C}$ for hybridization for $1 \mathrm{~h}$. The second antibody was then applied at $37^{\circ} \mathrm{C}$ for hybridization for $1 \mathrm{~h}$, before the use of TBST and color reaction for $5 \mathrm{~min}$ with autoradiography. Quantity One for optical density value analysis and measurement was used. The results are shown as specimen optical density value/ $\beta$-actin optical density.

Nude mouse vaccination. Ten male nude mice, aged 6-8 weeks and weighing $\sim 20 \mathrm{~g}$ were used. The anumals were cared for by the Animal Experimental Center of Jilin University 

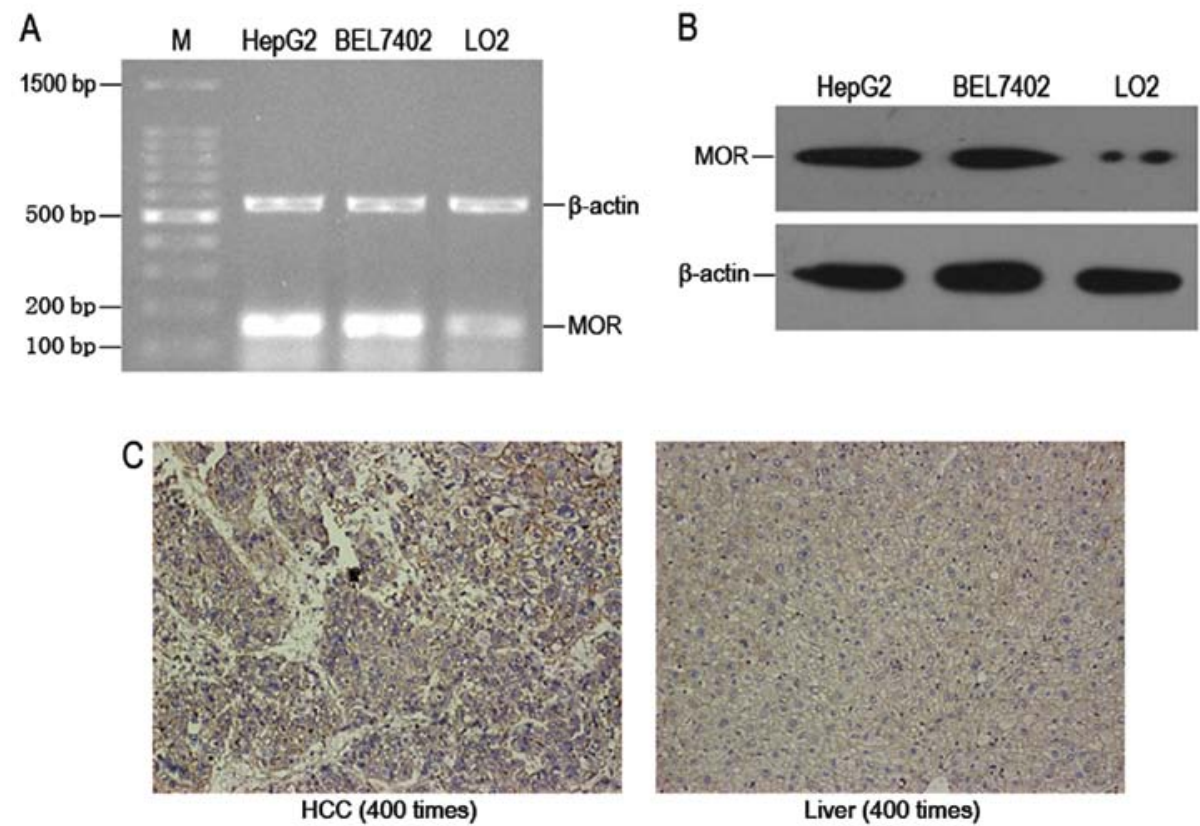

Figure 1. MOR expression in human hepatoma carcinoma cells and tissues. The results were repeated three times. (A) RT-PCR analysis on MOR gene expression. (B) Western blot analysis on MOR protein expression. (C) Immunohistochemical analysis on MOP expression in human hepatoma carcinoma tissues and normal liver tissues.

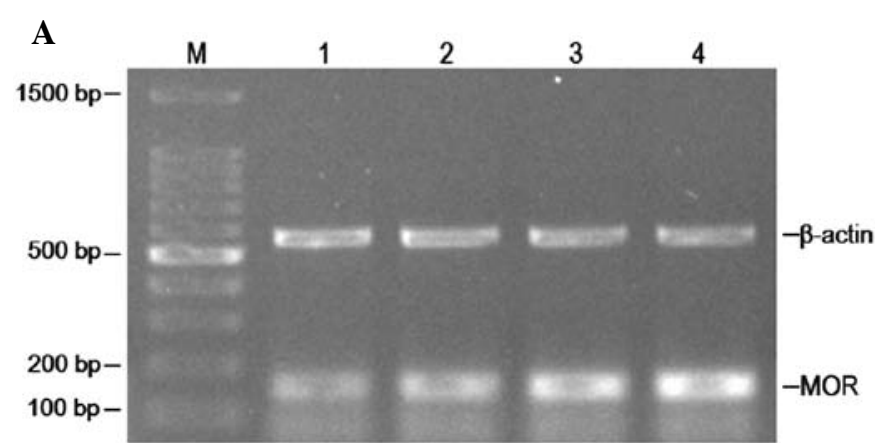

B

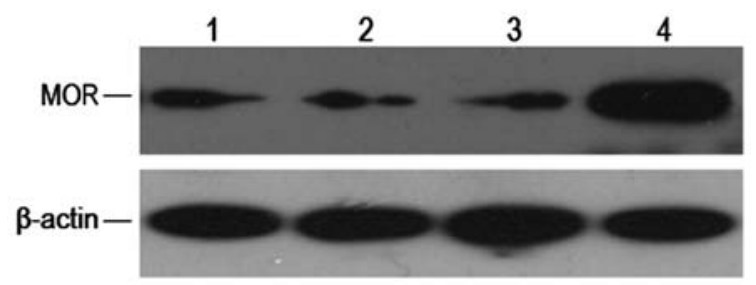

Figure 2. Use of RNA interference to silence MOR gene expression in HepG2 cells. (A) RT-PCR determination of interference efficiency for MOR siRNA transfected HepG2 cells at various time points. Lane M, 1500 bp Marker. Lane 1, MOR siRNA transfection for $24 \mathrm{~h} ; 2$, MOR siRNA transfection for $48 \mathrm{~h} ; 3$, MOR siRNA transfection for $72 \mathrm{~h}$; 4, Transfection negative control oligonucleotide group. (B) Further analysis of interference efficiency with western blotting. Lane 1, MOR siRNA transfection for $24 \mathrm{~h} ; 2$, MOR siRNA transfection for $48 \mathrm{~h}$; 3, MOR siRNA transfection for $72 \mathrm{~h} ; 4$, Transfection negative control oligonucleotide group.

(Changchun, China). The animal experimental plan was approved by the medical ethics committee of Jilin University. The mice were randomly divided into two groups of 5 mice each. The animals were vaccinated with the cells of control group and MOR siRNA group, respectively. Each mouse was injected with $1 \times 10^{5}$ cells. The growth of the nude mice were observed every day, and after four weeks the mice were sacrificed. The subcutaneous transplanted tumor tissue was cut, under aseptic condition, for index analysis.

Statistical analysis. SPSS 17.0 statistical software was used for the statistical analysis. The values are shown as the mean \pm SD. The statistical analysis was performed using the Student's $\mathrm{t}$-test, and the differences between the groups were considered to be statistically significant at $\mathrm{p}<0.05$.

\section{Results}

MOR expression in human hepatoma carcinoma cells and tissues. RT-PCR and western blotting were employed by us to analyze the expression of MOR mRNA and protein in human hepatoma carcinoma cells. It was found that there was high expression of MOR mRNA in HepG2 cells and BEL7402 cells (Fig. 1A). The expression of MOR protein in HepG2 cells and BEL7402 cells was similar to that of mRNA (Fig. 1B). Moreover, it was found by the immunohistochemical analysis that MOR expression in human hepatoma carcinoma tissues was obviously higher than that in normal human liver tissues (Fig. 1C).

RNA interference to silence MOR gene expression. We used MOR siRNA and negative control oligonucleotide to transfect HepG2 cells and observed the MOR mRNA and protein expression of transfections under various conditions. We found that $45 \mathrm{nM}$ of MOR siRNA transfection for $24 \mathrm{~h}$ could significantly reduce the expression level of MOR mRNA, and the expression level of MOR protein declined accordingly. This efficiency can endure at least for $72 \mathrm{~h}$ (Fig. 2A and B). This indicates that MOR siRNA transfection could effectively silence the MOR gene and affect the expression of MOR expression in turn. 

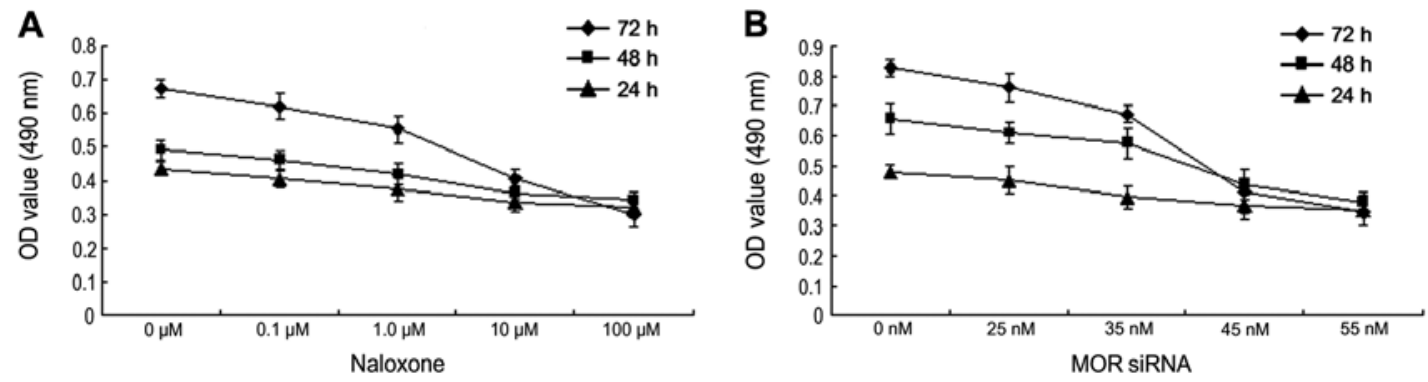

Figure 3. Downregulating MOP to inhibit human hepatoma carcinoma cell growth. The results were repeated three times. (A) MTT method to test cell viability after various concentrations of Naloxone $(0,0.1,1.0,10,100 \mu \mathrm{M})$ on HepG2 cells for 24,48 and $72 \mathrm{~h}$. (B) MTT method to test cell viability after various concentrations of MOP siRNA $(0,25,35,45,55 \mathrm{nM})$ on HepG2 cells for 24, 48 and $72 \mathrm{~h}$.

A
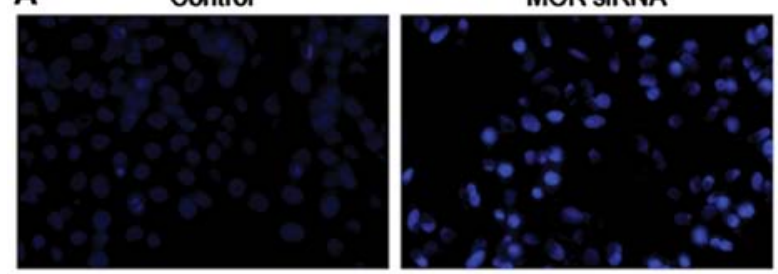

B
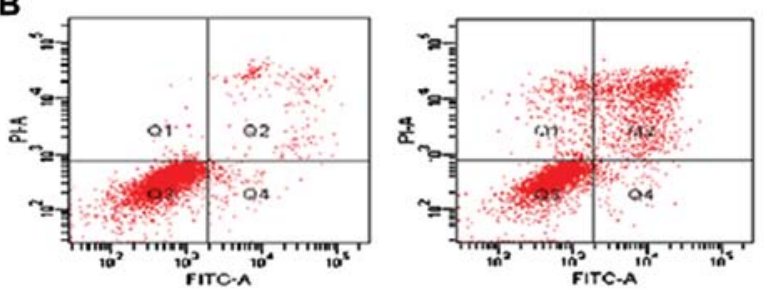

Naloxone
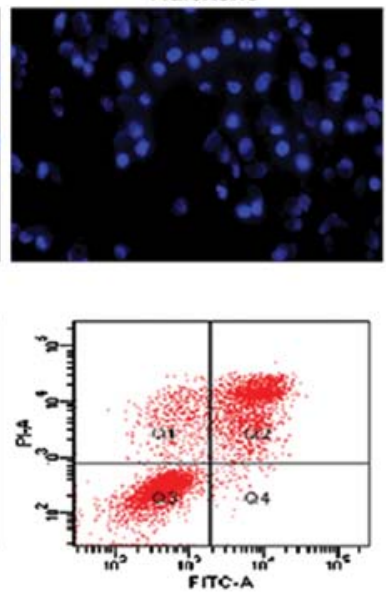

D

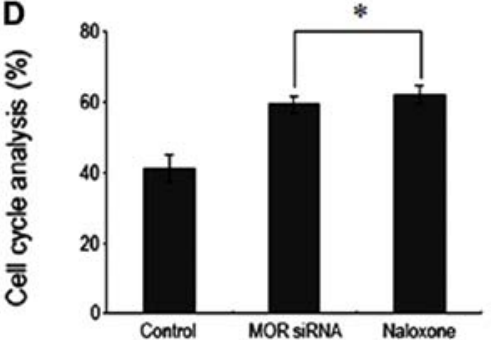

$\mathbf{F}$

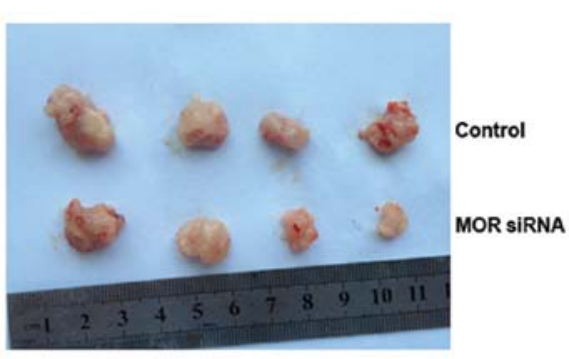

Time after inoculation (day)

Figure 4. Downregulation of MOR to promote apoptosis of human hepatoma carcinoma cells. (A) Hoechst 33342 dye fluorescence microscope to observe cell apoptosis. (B) Flow cytometry to test apoptosis rate. (C) Histogram to show the cell apoptosis rate (\%). (AD) Flow cytometry to analyze the cell cycle after PI coloration. ${ }^{*} \mathrm{p}<0.05$. The results were repeated three times. (E) The tumor volume at various time points after vaccination. (F) Tumor tissues of the nude mice 21 days after the vaccination from resection.

Downregulating MOR to inhibit human hepatoma carcinoma cell growth. In order to verify the impact of downregulating MOR on human hepatoma carcinoma cell growth, Naloxone of various concentrations $(0,0.1,1.0,10,100 \mu \mathrm{M})$ and MOR
siRNA of various concentrations $(0,25,35,45,55 \mathrm{nM})$ were administered to treat human hepatoma carcinoma HepG2 cells for 24, 48 and $72 \mathrm{~h}$ before MTT analysis on cell viability (Fig. 3A and B). As indicated in the results, with the increase 

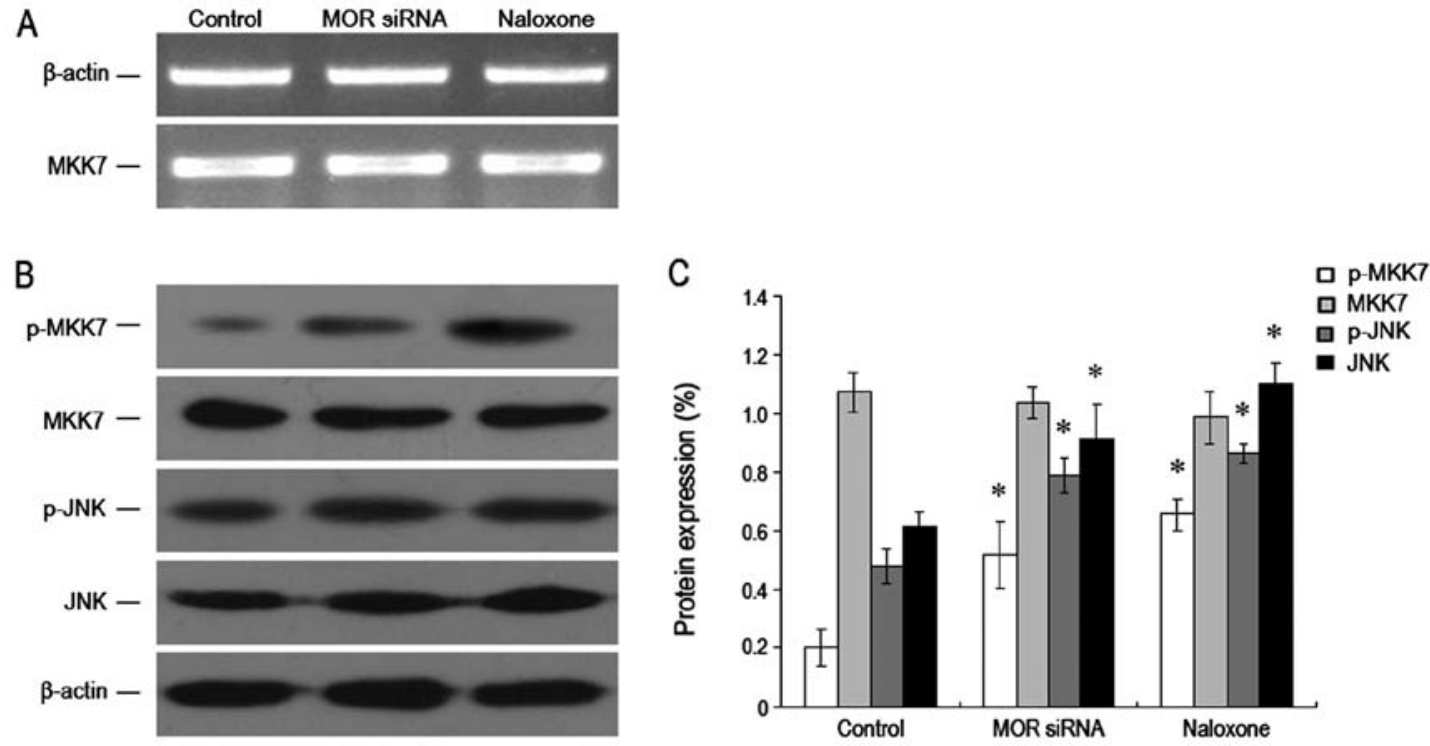

Figure 5. Downregulation of MOR to increase phosphorylated MKK7 and JNK expression. (A) RT-PCR analysis on MKK7 mRNA expression level. (B) Western blot analysis on expression levels of total MKK7, phosphorylated MKK7, total JNK and phosphorylated JNK. (C) Histogram to show (B) (\%). "p<0.05. The results were repeated three times.

of the concentrations of Naloxone and MOR siRNA, A490 value of HepG2 cells reduced. Such a result means that downregulating MOR can inhibit the growth of human hepatoma carcinoma cells.

Downregulation of MOR to promote apoptosis of human hepatoma carcinoma cells. In order to explore whether downregulating MOR results in apoptosis of human hepatoma carcinoma cells, we used Hoechst 33342 stain and flow cytometry to observe apoptosis of human hepatoma carcinoma cells. The results indicated that after the administration of Naloxone and MOR siRNA to treat human liver cancer HepG2 cells, the cell's chromatin concentrated with the brightness obviously higher than the normal control group (Fig. 4A). The apoptosis rate was 18.36 and $22.99 \%$, respectively, which are both higher than the $6.6 \%$ of the control group (Fig. 4B and C). This indicates that downregulation of MOR can promote apoptosis of human hepatoma carcinoma cell to inhibit the growth of human hepatoma carcinoma cells in turn.

Downregulation of MOR to block the cycle of human hepatoma carcinoma cells. In order to study whether downregulating MOR has any impact on the progress of the cycle of human hepatoma carcinoma cells, we used flow cytometry to analyze the cell cycle. The results indicated that after HepG2 cells were treated with the administration of Naloxone and MOR siRNA, the number of cells remaining in the G0/G1 stage increased significantly and was higher than that of the control group (Fig. 4D). Therefore, downregulation of MOR functions inhibiting the progress of the human hepatoma carcinoma cell cycle, so as to inhibit cell growth.

Downregulation of MOR to inhibit nude mouse tumor growth. We used the nude mouse model to establish the in vitro tumors. After 4 weeks, the five nude mice of the normal control group all had tumors with the tumor formation rate of $100 \%$. Four nude mice in the MOR siRNA group had tumors with the tumor formation rate of $80 \%$. In addition, the tumors of the nude mice in the control group grew faster than those in the MOR siRNA group (Fig. 4E and F). These results evidenced that downregulation of MOR can distinctly inhibit the tumor progress in vivo.

Downregulation of MOR to increase phosphorylated MKK7 expression. In order to verify the molecular mechanism for downregulating MOR to inhibit the growth of human hepatoma carcinoma cells, we used RT-PCR and western blotting, respectively, to test the MKK7 mRNA and MKK7 proteins and their phosphorylation levels. We found that after MOR was downregulated, the total protein expression level of MKK7 mRNA and MKK7 was not obviously changed, while the MKK7 phosphorylation level was significantly increased and was higher than that of the control group. Moreover, we found JNK and its phosphorylation level also increased drastically (Fig. 5A-C). These results show that downregulating MOR can increase the expression level of phosphorylation MKK7 (but not for all MKK7), which results in JNK and its phosphorylation level. This may be its molecular mechanism to inhibit the growth of hepatoma carcinoma cells.

RNA interference role to silence MKK7 for reversal of MOR to inhibit growth of human hepatoma carcinoma cells. In order to demonstrate whether MKK7 plays a key role in the inhibition of the growth of human hepatoma carcinoma cells via downregulation of MOR, we used RNA interference to silence MKK7 expression and observed the growth of human hepatoma carcinoma cell. The results showed that after MKK7 was silenced, A490-nm value of the hepatoma carcinoma cells was apparently on the increase as compared to that in the group with downregulating MOR. At the same time, JNK and its phosphorylation level dropped signifi- 

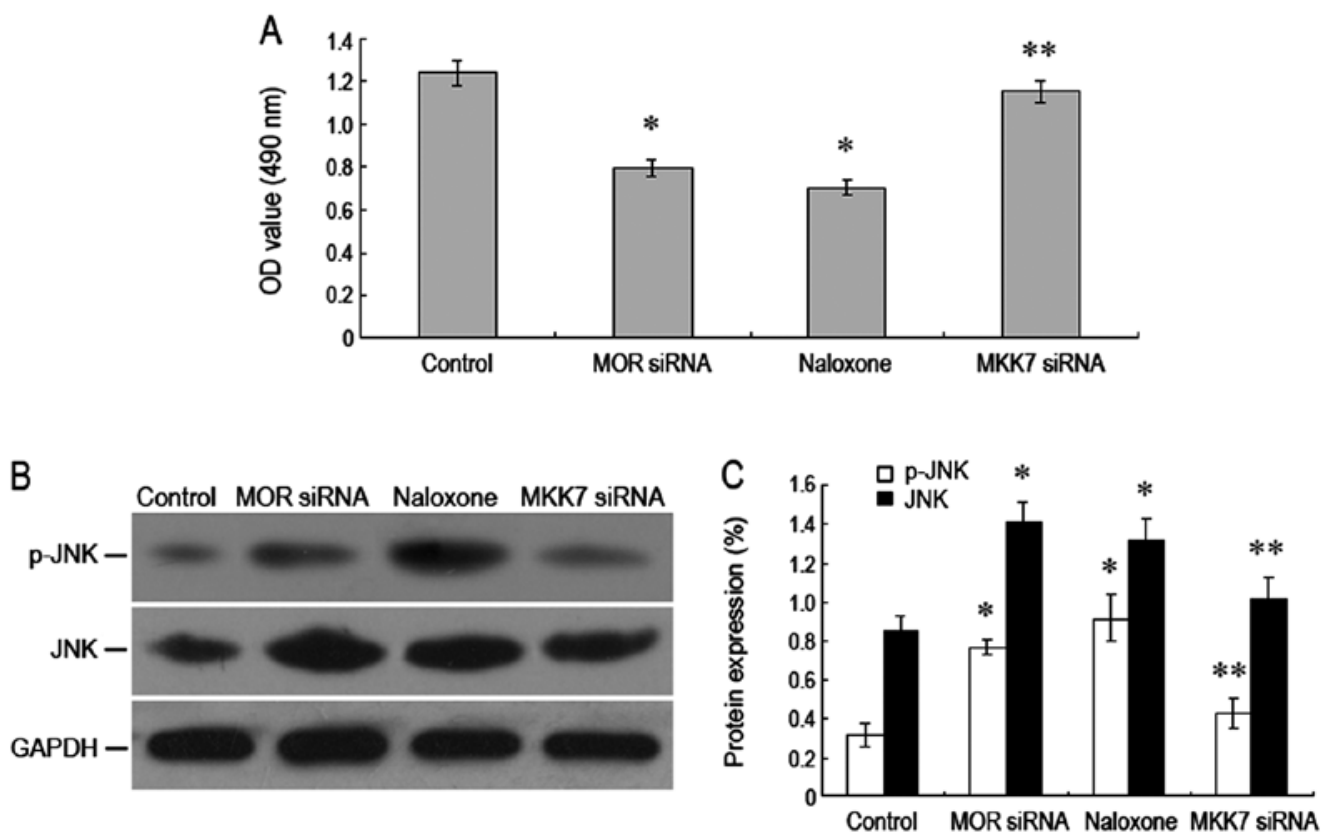

Figure 6. Inhibition of growth of human hepatoma carcinoma cells, and decline of JNK and its phosphorylation level induced by silencing MKK7 to reverse and downregulate MOR. (A) MTT method to test the cell proliferation rate. (B) Western blot to analyze JNK and its phosphorylated protein expression level. (C) Histogram to show (B) (\%). "p<0.05. The results were repeated three times.

cantly (Fig. 6A-C). Our data indicated that the inhibition of the growth of human hepatoma carcinoma cells via downregulation of MOR may be through the JNK pathway mediated by the MKK7 pathway.

\section{Discussion}

$\mu$-opioid receptor (MOR) is a member of the opioid receptor super-family, and its role in antitumor has gained a great deal of attention. Previous studies have shown that MOR can participate in the progress of many solid tumors via affecting the proliferation and apoptosis of tumor cells $(9,10,12)$. In this study, we mainly focused on exploring the impact of downregulation of MOR on the progress of human liver cancer and its molecular mechanism. Our study findings were similar to the above reports. We found the expression level of MOR in human hepatoma carcinoma cells and tissue were far higher than that in the normal liver cells and tissue, and they were mainly on the surface of the cell membrane. This indicated that MOR may participate, playing a key role, in the human liver cancer development.

The impact of MOR on liver cancer was previously unknown. However, MOR plays a significant role in protecting neuronal cells, myocardial cells and intestinal mucosa cells. Iglesias et al (19) found in their studies, that MORactivation may prevent apoptosis of SH-SY5Y cells and cerebral cortex neurons caused by serum withdrawal via PI3-K/AKT signal pathway. Maslov et al (20) found in the cardiac ischemia-reperfusion injury that MOR agonist plays a significant role in protecting acute IRI and it is closely related to KATP pathway. Gross et al (21) reported that a neotype enkephalin derivative EP94 can reduce the MI area of the rat via activating MOR. In addition, the studies of Goldsmith et al (22) demonstrated that MOR may promote the healing of the mouse acute intestinal injury via activating the Stat3 pathway. Although there might be a specific difference between the liver tumor cells and the normal cells such as myocardial cells in our study, our study findings are similar to those in the studies mentioned above. It is indicated in our findings that the expression level of MOR in human hepatoma carcinoma cells increased significantly, which means MOR played a key role in the proliferation and differentiation of hepatoma carcinoma cells. However, its specific role and relevant mechanism deserve further verification.

To date, there have been few studies on the MOR in the generation and progress of human tumors and many questions remain to be effectively explained. Lennon et al (9) found in their studies that the overexpression of MOR could promote the activation of Akt and mTOR resulting in the tumor growth and metastasis. Mathew et al (23) found high expression of MOR in human lung cancer and MOR promotion of tumor progress. In our study, we found downregulation of MOR could obviously inhibit the proliferation of human hepatoma carcinoma cells with increased cell apoptosis rate and the blockade of cell cycle in the G0/G1 stage. Moreover, in in vivo experiments, the growth of the tumors of the mice retarded greatly indicating that MOR overexpression in human hepatoma carcinoma cells and tissue plays a positive regulation role in the progress of liver cancer.

Mitogen activated protein kinase (MAPK) signal transduction pathway consists of a large family of kinases for the cell to respond to exogenous and endogenous stimuli $(24,25)$. These three main MAPKs, JNK, p38 MAPK and ERK play important roles in regulating the response of tissue cells (26). In addition, JNK is widely recognized as the intracellular signal transduction enzyme associated with cell proliferation, differentiation and apoptosis. The high expression of JNK1 and JNK2 in tissues affect the development of many types of cancer $(27,28)$. As an important member of a three-level cascade reaction, phosphorylated MKK7 may specifically 
activate the JNK signal pathway, and regulate cell growth, differentiation and apoptosis, as previously indicated (29). MKK7 (SEK2) is a component of MAPK signal transduction pathway and a direct upstream kinase that phosphorylates Thr-183 and Tyr-185 in JNK VIII area to activate JNK to transduce extracellular stimulation signal to the cell and nucleus for the cells to have a series of biological reactions. Thus, their inactivation can block the JNK signal transduction pathway and is a good approach to control cell damage.

Tang et al (30) found in the in vitro experiments and studies that Alpinetin can inhibit the proliferation of human hepatoma carcinoma cells and increase its sensitivity to cisplatin, a chemotherapy drug via activating the MKK7/JNK signal pathway. Therefore, the activation of MKK7 is a crucial factor in our study. Previous studies demonstrated that MOR can play its role via PTX-senstive G protein signal transduction pathway (31) and KATP signal transduction pathway (32). Moreover, Wang et al (33) found that MOR plays its regulating role via PKC/MAPK pathway. Our results show that downregulation of MOR may result in the increase of MKK7 phosphorylation to trigger the increase of JNK protein and its phosphorylation level to inhibit the proliferation of cells. In addition, we saw that after MKK7 was blocked by RNA interference, degardless of downregulation of MOR or not, as the cell proliferation was not affected. Therefore, our conclusion is that the main function of downregulating MOR is to inhibit the proliferation of human hepatoma carcinoma cells, while activated MKK7 provides an important strategy for this.

Collectively, it is demonstrated by our study that downregulation of MOR may activate JNK signal transduction pathway via regulating MKK7 phosphorylation level so as to obviously inhibit the proliferation of hepatoma carcinoma cells and cause tumor growth retardation. MOR may make important contributions by being a new approach to prevent and treat liver tumors.

\section{Acknowledgements}

We thank Dr Zhenran Wang for advice on the manuscript preparation.

\section{References}

1. El-Serag HB and Rudolph KL: Hepatocellular carcinoma: epidemiology and molecular carcinogenesis. Gastroenterology 132 2557-2576, 2007.

2. Rampone B, Schiavone B, Martino A, Viviano C and Confuorto G: Current management strategy of hepatocellular carcinoma. World J Gastroenterol 15: 3210-3216, 2009.

3. Rahbari NN, Mehrabi A, Mollberg NM, Müller SA, Koch M, Büchler MW and Weitz J: Hepatocellular carcinoma: current management and perspectives for the future. Ann Surg 253: 453-469, 2011.

4. Merle P and Mornex F: Medical therapies for hepatocellular carcinoma. Cancer Radiother 15: 28-31, 2011 (In French).

5. Kim E, Clark AL, Kiss A, Hahn JW, Wesselschmidt R, Coscia CJ and Belcheva MM: Mu- and kappa-opioids induce the differentiation of embryonic stem cells to neural progenitors. J Biol Chem 281: 33749-33760, 2006

6. Brillet K, da Conceição MM, Pattus F and Pereira CA: Bioprocess parameters of cell growth and human mu opioid receptor expression in recombinant Drosophila $\mathrm{S} 2$ cell cultures in a bioreactor. Bioprocess Biosyst Eng 28: 291-293, 2006.
7. Gein SV, Simonenko TA and Chereshnev VA: Effect of betaendorphin and DAGO, a selective agonist of mu-opioid receptors, on the proliferative activity of lymphocytes. Dokl Biol Sci 391: 289-291, 2003

8. Harburg GC, Hall FS, Harrist AV, Sora I, Uhl GR and Eisch AJ: Knockout of the mu opioid receptor enhances the survival of adult-generated hippocampal granule cell neurons. Neuroscience 144: 77-87, 2007.

9. Lennon FE, Mirzapoiazova T, Mambetsariev B, Salgia R, Moss J and Singleton PA: Overexpression of the $\mu$-opioid receptor in human non-small cell lung cancer promotes Akt and mTOR activation, tumor growth, and metastasis. Anesthesiology 116: 857-867, 2012.

10. Bortsov AV, Millikan RC, Belfer I, Boortz-Marx RL, Arora H and McLean SA: $\mu$-Opioid receptor gene A118G polymorphism predicts survival in patients with breast cancer. Anesthesiology 116: 896-902, 2012.

11. Yuen JW, So IY, Kam AY and Wong YH: Regulation of STAT3 by mu-opioid receptors in human neuroblastoma SH-SY5Y cells. Neuroreport 15: 1431-1435, 2004.

12. Nylund G, Pettersson A, Bengtsson C, Khorram-Manesh A, Nordgren S and Delbro DS: Functional expression of mu-opioid receptors in the human colon cancer cell line, HT-29, and their localization in human colon. Dig Dis Sci 53: 461-466, 2008.

13. Chang L and Karin M: Mammalian MAP kinase signalling cascades. Nature 410: 37-40, 2001

14. Molton SA, Todd DE and Cook SJ: Selective activation of the c-Jun N-terminal kinase (JNK) pathway fails to elicit Bax activation or apoptosis unless the phosphoinositide 3'-kinase (PI3K) pathway is inhibited. Oncogene 22: 4690-4701, 2003.

15. Dérijard B, Raingeaud J, Barrett T, Wu IH, Han J, Ulevitch RJ and Davis RJ: Independent human MAP-kinase signal transduction pathways defined by MEK and MKK isoforms. Science 267: 682-685, 1995.

16. Kishimoto H, Nakagawa K, Watanabe T, Kitagawa D, Momose H, Seo J, Nishitai G, Shimizu N, Ohata S, Tanemura S, Asaka S, Goto T, Fukushi H, Yoshida H, Suzuki A, Sasaki T, Wada T, Penninger JM, Nishina $\mathrm{H}$ and Katada T: Different properties of SEK1 and MKK7 in dual phosphorylation of stress-induced activated protein kinase SAPK/JNK in embryonic stem cells. J Biol Chem 278: 16595-16601, 2003.

17. Tournier C, Dong C, Turner TK, Jones SN, Flavell RA and Davis RJ: MKK7 is an essential component of the JNK signal transduction pathway activated by proinflammatory cytokines. Genes Dev 15: 1419-1426, 2001.

18. Wang X, Destrument A and Tournier C: Physiological roles of MKK4 and MKK7: insights from animal models. Biochim Biophys Acta 1773: 1349-1357, 2007.

19. Iglesias M, Segura MF, Comella JX and Olmos G: Mu-opioid receptor activation prevents apoptosis following serum withdrawal in differentiated SH-SY5Y cells and cortical neurons via phosphatidylinositol 3-kinase. Neuropharmacology 44: 482-492, 2003.

20. Maslov LN, Lasukova TV, Solenkova NV, Lishmanov AIu, Bogomaz SA, Tam SV and Gross GJ: Participation of K(ATP)channels in cardioprotective effect of mu-opioid receptor agonists in acute ischemia and reperfusion of the isolated heart. Eksp Klin Farmakol 64: 23-27, 2001 (In Russian).

21. Gross GJ, Hsu A, Nithipatikom K, Bobrova I and Bissessar E: Eribis peptide 94 reduces infarct size in rat hearts via activation of centrally located $\mu$ opioid receptors. J Cardiovasc Pharmacol 59: 194-197, 2012.

22. Goldsmith JR, Uronis JM and Jobin C: Mu opioid signaling protects against acute murine intestinal injury in a manner involving Stat3 signaling. Am J Pathol 179: 673-683, 2011.

23. Mathew B, Lennon FE, Siegler J, Mirzapoiazova T, Mambetsariev N, Sammani S, Gerhold LM, LaRiviere PJ, Chen CT, Garcia JG, Salgia R, Moss J and Singleton PA: The novel role of the mu opioid receptor in lung cancer progression: a laboratory investigation. Anesth Analg 112: 558-567, 2011.

24. Galeotti N and Ghelardini C: Regionally selective activation and differential regulation of ERK, JNK and p38 MAP kinase signalling pathway by protein kinase $\mathrm{C}$ in mood modulation. Int J Neuropsychopharmacol 20: 1-13, 2011.

25. Raman M, Chen W and Cobb MH: Differential regulation and properties of MAPKs. Oncogene 26: 3100-3112, 2007.

26. Kim EK and Choi EJ: Pathological roles of MAPK signaling pathways in human diseases. Biochim Biophys Acta 1802: 396-405, 2010 
27. Bermudez O, Pagès G and Gimond C: The dual-specificity MAP kinase phosphatases: critical roles in development and cancer Am J Physiol Cell Physiol 299: C189-C202, 2010.

28. Huang P, Han J and Hui L: MAPK signaling in inflammationassociated cancer development. Protein Cell 1: 218-226, 2010.

29. Haeusgen W, Herdegen T and Waetzig V: The bottleneck of JNK signaling: molecular and functional characteristics of MKK4 and MKK7. Eur J Cell Biol 90: 536-544, 2011.

30. Tang B, Du J, Wang J, Tan G, Gao Z, Wang Z and Wang L: Alpinetin suppresses proliferation of human hepatoma cells by the activation of MKK7 and elevates sensitization to cisdiammined dichloridoplatium. Oncol Rep 27: 1090-1096, 2012.
31. Giaroni C, Zanetti E, Vanti A, Canciani L, Lecchini S and Frigo G: Sympathetic denervation-induced changes in $\mathrm{G}$ protein expression in enteric neurons of the guinea pig colon. Life Sci 71: 1961-1973, 2002.

32. Chen ZC, Shieh JP, Chung HH, Hung CH, Lin HJ and Cheng JT: Activation of peripheral opioid $\mu$-receptors in blood vessel may lower blood pressure in spontaneously hypertensive rats. Pharmacology 87: 257-264, 2011.

33. Wang Q and Traynor JR: Modulation of $\mu$-opioid receptor signaling by RGS19 in SH-SY5Y cells. Mol Pharmacol 83: 512-520, 2013 